\title{
STOCHASTIC TECHNO-ECONOMIC CONSIDERATIONS IN BIODIESEL PRODUCTION
}

\author{
Usman Abubakar, Srinivas Sriramula* and Neill C. Renton
}

School of Engineering, University of Aberdeen, Aberdeen, AB24 3UE, United Kingdom

*Corresponding author: Srinivas Sriramula

Lloyd's Register Foundation (LRF) Centre for Safety \& Reliability Engineering,

School of Engineering, University of Aberdeen

Aberdeen, AB24 3UE, UK.

Phone: +44 (0)1224 272778, Fax: +44 (0) 1224-272497

Email: s.sriramula@abdn.ac.uk 


\section{ABSTRACT}

Biodiesel production, like other engineering projects, involves critical decisions which have to be made under uncertainties stemming from a range of sources such as the inherent variation in operating conditions and market forces featuring inflation, depreciation factors, variations in equipment/production costs, etc. Although the effect of such uncertainties on front end engineering and management decisions was recognised, these have not been considered comprehensively in the literature. In this paper, for the first time, structural reliability principles are applied to determine the prospect of a process plant achieving some performance targets under uncertainties. Considering the published case of a biodiesel production plant, this paper presents a new approach for techno-economic assessment in a stochastic framework. Mean values of the economic indicators obtained through the stochastic analysis are found to be in good agreement with previously published nominal values. The stochastic techno-economic analysis approach combines First Order Reliability Method (FORM) and Monte Carlo Simulation (MCS) to offer additional performance measures which are needed by prospective investors, governments, engineers and other stakeholders to ensure plant safety and cost-efficiency.

Keywords: Biodiesel production process; Techno-economic analysis; Uncertainty; Plant performance optimization; Stochastic modelling. 


\subsection{INTRODUCTION}

Biodiesel has a number of advantages over the conventional petrodiesel; it is renewable, biodegradable, non-toxic, carbon neutral, has lower sulphur content, high lubricity and better flash point [1]. Service properties of biodiesel are very similar to those of conventional diesel; this makes it possible to blend the duo in all proportions [1,2]. On the other hand, biodiesel production faces certain technical and economic challenges as well as uncertainties in sustainability and market forces. Some of the concerns associated with biodiesel usage are storage, low-temperature performance characteristics, $N O_{x}$ exhaust emissions, high breakeven cost, the tendency to compete with food sources and costing 1.5 to 3.0 times the conventional diesel price. Also, in terms of heating value, biodiesel has slightly lower calorific value $(42.65 \mathrm{MJ} / \mathrm{kg})$ than petrodiesel $(43 \mathrm{MJ} / \mathrm{kg})$ and gasoline $(46 \mathrm{MJ} / \mathrm{kg})$, but performs better than coal $(32-37 \mathrm{MJ} / \mathrm{kg})[3]$.

Considerable progress in the development of biodiesel production technologies has already been reported. Use of Waste Cooking Oil (WCO) as feedstock for production of biodiesel appears to be a promising way to address issues such as the high breakeven unit price and the fuel-against-food problem [4-6]. Zhang et al. [7] modelled and evaluated four different biodiesel production processes involving both virgin and waste cooking oil; employing both heterogonous and homogenous catalysis. A subsequent economic assessment concluded that none of the four processes was able to result in a net positive after tax rate of return [8]. However, among the four processes, homogenous acid-catalysed process was shown to be potentially viable in terms of both returns and technological requirements. West et al. [9] extended the works of Zhang et al. [7,8] by modifying the design configurations, employing fewer unit operations with smaller capacities and reducing the need for stainless steel (by changing certain reacting conditions including the type of catalyst) and confirmed that acid catalysed process could be a practical biodiesel production pathway. For the same plant capacity $(8000$ ton $/ y r)$, depreciation rate $(10 \%)$, income tax rate $(50 \%)$ and other economic conditions, West et al. [9] showed that the capital cost can be cut down from $\$ 2.55 \mathrm{M}$ to 
$\$ 0.63 M$ and the total production cost from $\$ 5.92 M$ to $\$ 4.45 M$, bringing down the after tax rate of return from $-15.63 \%$ to $+58.76 \%$.

Depending on plant capacity and type of feedstock, among other factors, different technoeconomic assessments of biodiesel production processes suggest different breakeven unit prices. For instance, the four processes presented by Zhang et al. [8] indicated that the required selling price for biodiesel ranges from 644 to $884 \$$ /ton (plant capacity: 8000tons / yr); Encinar et al. [10] estimated this to be 537 \$/ton and van Kasteren \& Nisworo [11] observed that the biodiesel minimum selling price could be $202 \$ /$ ton, $282 \$ /$ ton and $623 \$ /$ ton for plant capacities of 125,000 ton $/ y r, 80,000$ ton $/ y r$ and 8,000 ton $/ y$ r, respectively. Similarly, different figures for investment costs, production costs, etc. were observed; emphasising the need for considering uncertainties in these estimates within a probabilistic framework. Usually, assuming input/output linearity in terms of uncertainty, a fixed error limit is imposed implicitly to account for the effect of such uncertainties. However, such an assumption does not scale or gauge the specific quantities within a given range in terms of likelihood of occurrence. For instance, with reference to the breakeven price range reported in Zhang et al. [8], i.e. 644 to $884 \$ /$ ton, it would be beneficial to know the:

- probability of recovering the investment cost when the biodiesel is sold at a target breakeven price of $U_{B \max }^{*} \$ /$ ton;

- confidence level associated with the entire price range;

- $\quad$ probability that the net after tax profit is greater than or equal to a certain threshold $P_{\min }$ throughout the life of the plant;

- most probable design/operational specifications for a plant to achieve a defined performance target ; and

- probability distribution of different economic indicators, the sensitivity of selected financial indices to given variables or the reliability associated with certain critical investment decisions. 
To provide such deep insights, stochastic uncertainty modelling together with reliability analysis is usually recommended $[12,13]$. The proposed stochastic framework is designed to address these questions.

Uncertainties in the technology and economic forces are among the major sources of concern. There are a number of uncertainty sources in biodiesel production including random input/process variations due to changes in the composition of WCO, which originate from different sources; these can ultimately affect annual plant tonnage in terms of biodiesel and glycerine production. In addition, uncertainties in market forces such as inflation, depreciation factors, variations in the cost of equipment, production costs, etc. are also likely to affect the credibility of the usual deterministic estimates, especially during the early development phase. For instance, Thompson et al. [14] opined that effects of uncertainty on the market of feedstock are very significant and argued that considering them as constant represents over simplification. Other sources of concern include modelling and statistical uncertainties arising from lack of data, simplifications as well as lack of knowledge; these various sources of uncertainties come together and propagate across various project development phases and impact the techno-economic performance estimates.

Being a new venture, potential investors would always desire to understand not only the prospects, but the uncertainties, including the underlying risk. Probabilistic design/economic modelling and analysis could help provide a rational basis for supporting critical decisions by offering various stochastic measures $[15,16]$. It is seen that research studies discussed so far did not offer these possibilities for biodiesel production. The present work seeks to bridge this gap by proposing an enhanced stochastic modelling approach to consider the technoeconomic viability of biodiesel production plants, considering a published case study. This work is an extension of the generic framework for optimising chemical process performance proposed in Abubakar et al. [17]. As the focus of this paper is on stochastic assessment, only a brief reference will be made to traditional deterministic approach, further information on these aspects is available elsewhere $[3,9,18,19]$. In addition, all the economic indicators 
considered in this paper are based on a fixed-capacity, heterogonous catalysed biodiesel production plant using WCO and methanol as feedstock; this relaxes the effect of plant capacity on the economic indicators such as the breakeven unit price of biodiesel. Studies on the effect of plant capacity on breakeven price of biodiesel were considered by Torres et al. [20]. Before presenting the stochastic modelling approach, a brief overview of the design and conditions for biodiesel production and economic considerations will be given in what follows.

\subsection{CONSIDERED CASE STUDY: BIODIESEL PRODUCTION PLANT}

A heterogeneous acid-catalyzed biodiesel production process is modelled using UniSim ${ }^{\circledR}$ Design software (other process simulators such as Aspen Hysys ${ }^{\circledR}$ can also be used) by considering the reaction kinetics, design specifications, total capital investment, revenues and overall economic viability. The raw materials are waste cooking oil (represented by Trioelein, a typical triglyceride molecule) and methanol in the presence of Tin(II) oxide as catalyst. Together with Glycerine, the biodiesel (Methyl- Oleate or Fatty Acid Methyl Ester (FAME)) is produced as shown in the reaction below [19]:

$$
\underset{(\text { WCO })}{\mathrm{C}_{57} \mathrm{H}_{104} \mathrm{O}_{6}}+3 \mathrm{CH}_{3} \mathrm{OH} \leftrightarrow \underset{\text { (Biodiesel) }}{3 \mathrm{C}_{19} \mathrm{H}_{36} \mathrm{O}_{2}}+\mathrm{C}_{3} \mathrm{H}_{5}(\mathrm{OH})_{3}
$$

The glycerol in triglycerides is replaced with a short-chain alcohol. Three consecutive reversible reactions are involved in the process: initially, the triglycerides are converted to diglycerides, then diglycerides are converted to monoglycerides and each monoglyceride molecule is then converted to glycerol; a total of three ester molecules are produced from each triglyceride molecule [3].

\subsection{Technology Description}

Waste cooking Oil (WCO) and methanol, in the presence of a solid catalyst (Tin (II) oxide), are fed into a reactor where the transesterification reaction takes place as depicted in Fig.1. The WCO, methanol and the catalyst are at an ambient temperature (about $25^{\circ} \mathrm{C}$ ), which is 
not optimal for the esterification reaction upstream. The stream at the bottom of the reactor, which contains a mixture of FAME (Biodiesel), glycerine, methanol, unreacted WCO and the catalyst, is at an elevated temperature (around $70^{\circ} \mathrm{C}$ ); this is charged into the heat exchanger (HEX) to warm up the incoming WCO feed as a means of enhancing energy efficiency. It is important to note that heat energy will have to be provided from external source to initiate the reaction and also to provide the balance required to drive the esterification reaction optimally. The mixture is then pumped into a hydrocyclone where the solid catalyst is separated by gravity. The remaining components of the mixtures are charged into a distillation column (Column1) where methanol is recovered and recycled to the reactor.

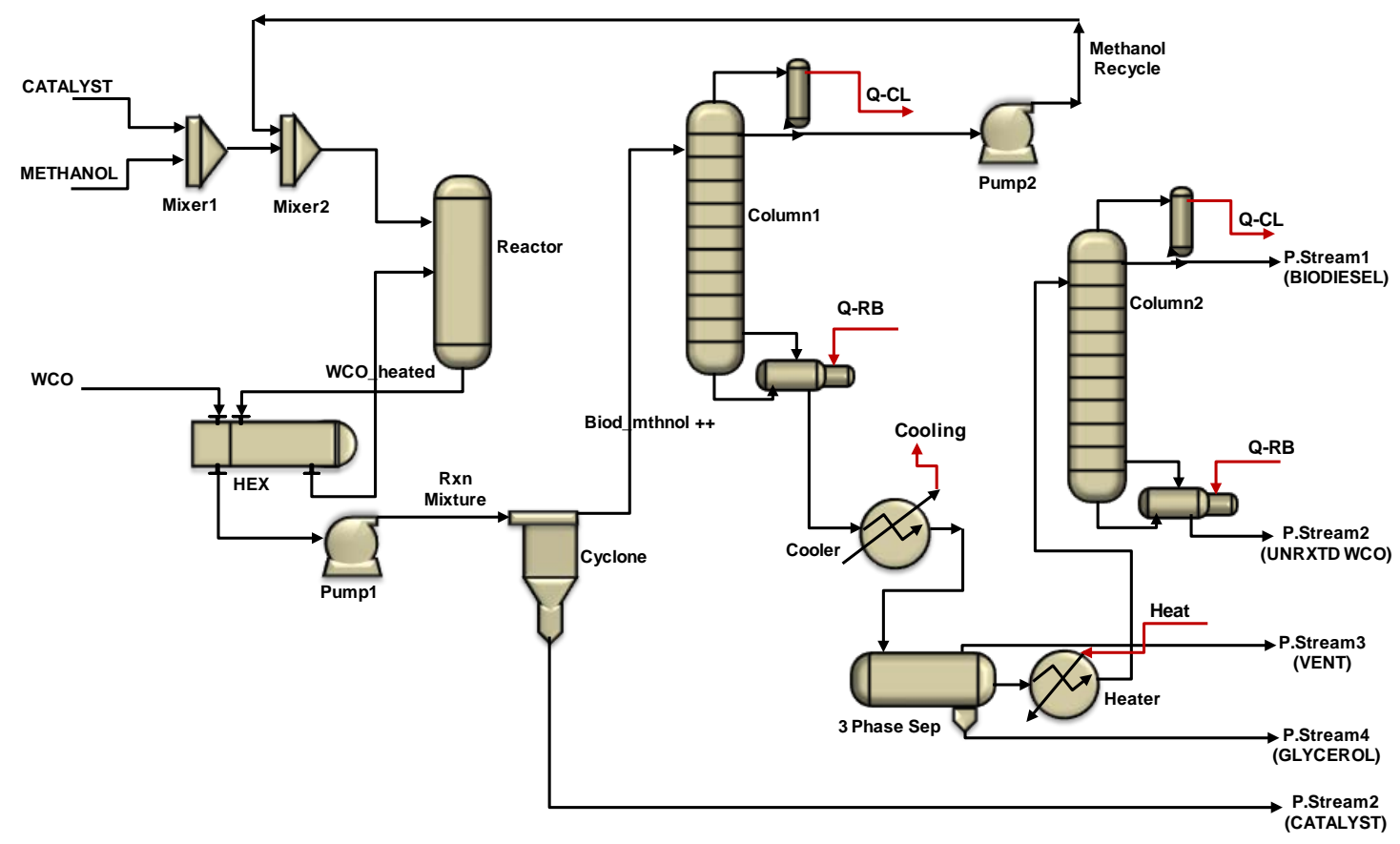

Figure 1: Heterogeneous acid catalysed biodiesel production process

Bottom stream of Column1 is cooled and drained into a 3-phase separator where glycerine is removed from P.Stream4, vent gases from P.Stream3 and the FAME rich stream is heated and charged into Column2 for further purification. Finally, biodiesel is removed from P.stream1 and the unconverted WCO together with other impurities is drained from P.Stream2. Details on specific equipment capacities including materials of construction are available in [9]. 


\subsection{DETERMINISTIC ECONOMIC EVALUATION}

A heterogeneous catalyzed biodiesel production process is modelled and simulated based on the studies by West et al. [9]. Total feedstock (WCO) rate, biodiesel production capacity and plant upstream time are 7900 ton/yr, 7840 ton/yr and 330 days/yr respectively $[9,19]$. The various process unit equipment needed to achieve the objectives are as in section 2.0.

The Total Capital Investment ( $\mathrm{TCl})$ is assumed to be disbursed over a period of three years (starting from " $-3 "$ ) before the plant start-up (at time zero). It is also assumed that $15 \%$ of the $\mathrm{TCl}$ is spent before year $-2,35 \%$ before year -1 and $50 \%$ before year 0 (start up). Inflation rate over this phase is assumed to be $2 \%$ per annum and the start up cost is assumed to be $10 \%$ of Fixed Capital Cost (FCC) [21]. A 20-year plant life is assumed [19] with depreciation rate set at $10 \%$ per annum; salvage value is assumed to be zero. Income tax rate is assumed to be $50 \%$ while keeping the production cost inflation at $2 \%$. The continuous operating plant is to be manned by three shift operators, each working for 49 weeks $/ y r$ at the rate of $32.6 \$ / h r$.

After the conceptual engineering design, the Front End Engineering Design (FEED) is necessary to provide basis for the next developmental phases i.e. detailed engineering, procurement and construction. The preliminary cost estimation, which is part of the FEED, requires the engineer to identify the main plant items, determine their respective capacities, appropriate material of construction and range of operating pressures and temperatures for each of the main process items. Preliminary cost estimate of a new chemical plant is usually based on historical data, implying that effect of time needs to be factored into the analysis. Hence, after estimating the equipment cost, it would have to be updated using one of the cost indexing schemes such Chemical Engineering Plant Cost Index (CEPCI), Marshall and Swift Process Industry Index (MSPII), Nelson-Farrar Refinery Construction index (NFRI) or Engineering News Record Construction Index (ENRCI) [12,13]. Also, both the direct and 
indirect costs along with the working capital need to be estimated to get the total capital investment costs.

A number of cost estimation methods can be used in the FEED phase including the Lang factor and module costing methods. Using Lang factor method, the Total Capital cost $\left(C_{T C I}\right)$ can be calculated as a product of the Lang factor and the purchased cost of equipment. The value of Lang factor depends on the phase of materials being handled; the Lang factors for fluid, solid-fluid and solid processing plant are 4.74, 3.63 and 3.10 respectively [12]. While Lang Factor method is relatively simple, it does not account for specific plant configurations, material of construction and higher working temperatures/pressures. On the other hand, module costing techniques are more demanding but address the problems encountered in using the Lang Factor methods [12]. There are a number of variants of the module cost estimates such as the Bare module cost for base and non-base case conditions $[12,13]$.

The main economic conditions used in this study are shown in Table 1 . The estimates are based on the work of Zhang et al. [8] where market conditions of year 2000 were considered. In this work, utility prices including the cost of catalysts have been updated to year 2013 using the Consumer price index [22]. Price of methanol and electricity were taken from Torres et al. [20]. The price of glycerine is highly dependent on its purity level, so instead of $750 \$ /$ ton reported in Zhang et al. [8], a selling price of $700 \$ /$ ton is assumed in this work. The price of process water is obtained from Abo El-Enin et al. [4]. Bare module factors $F_{B M}$, (shown in Table 2) for specific pieces of equipment, capacities and operating conditions are based on the works of Turton et al. [12] and Smith [13] while the individual equipment costs are adopted from West et al. [9]. 
Table 1: Considered economic conditions (based on the work of Zhang et al. [8])

\begin{tabular}{lc}
\hline Item & Price (\$/ton) \\
\hline WCO & 400 \\
Methanol & 211 \\
Tin(II) Oxide & 813.92 \\
Biodiesel & 1100 \\
Glycerol (85\% purity) & 700 \\
Cooling Water $\left(400 \mathrm{kPa} 6^{\circ} \mathrm{C}\right)$ & 0.01 \\
LP Steam $\left(601.3 \mathrm{kPa} 160^{\circ} \mathrm{C}\right)$ & 9.22 \\
HP Steam $\left(4201.3 \mathrm{kPa} 254^{\circ} \mathrm{C}\right)$ & 13.57 \\
Process Water (General) & 80 \\
Electricity & $25.77 \$ / G J$ \\
\hline
\end{tabular}

Based on the assumed economic conditions, as outlined above, the total equipment cost is estimated at $\$ 371,000$ reflecting the prevailing market conditions in year 2000 . For the same plant, West et al. [9] put the cost at $\$ 363,000$. On the other hand, the total bare module cost $(\$ 119,000)$ is updated to year $2013(\approx \$ 176,000)$ using Chemical Engineering Plant Cost Index (CEPCI) [23]. The cost correction factors [21], given in Table 3, are based on the delivered equipment cost.

Table 2: Estimation of total delivered module cost based on major process units

\begin{tabular}{|c|c|c|c|}
\hline Equipment & $\begin{array}{c}\text { Bare module factor } \\
F_{B M} \\
\text { (Turton et al. [12]) }\end{array}$ & $\begin{array}{c}\text { Bare Module } \\
\text { Cost }(\$) \\
\left(\times 10^{6}\right)\end{array}$ & $\begin{array}{c}\text { Delivered } \\
\text { equipment Cost } \\
(\$)\left(\times 10^{6}\right)\end{array}$ \\
\hline Reactor & 3.10 & 0.07480 & 0.02410 \\
\hline Methanol recovery & 4.00 & 0.02750 & 0.00688 \\
\hline Fame purification & 4.00 & 0.09340 & 0.02330 \\
\hline Heat exchanger & 3.30 & 0.07920 & 0.02400 \\
\hline Pumps $\times 2$ & 3.15 & 0.01360 & 0.00432 \\
\hline Hydrocyclone and others & 2.30 & 0.08280 & 0.03600 \\
\hline Total Cost (year 2000) & & 0.37100 & 0.11900 \\
\hline
\end{tabular}

Similarly, the total delivered equipment $\operatorname{cost} C_{E}^{o}$ is estimated based on the prevailing market situation in year 2000. The cost due to the auxiliary items and services are estimated using bare module factors (shown in Table 3). For similar plant specifications, West et al. [9] estimated the $\mathrm{TCl}$ at $\$ 0.630 \times 10^{6}$ (compare: $\$ 0.694 \times 10^{6}$ shown in Table 3 ). Using the $\mathrm{CEPCl}$, the $\mathrm{TCl}\left(\$ 0.694 \times 10^{6}\right)$ is then updated to year 2013 , giving $\$ 1.028 \times 10^{6}$. Further 
details on the cost of WCO, methanol and glycerine credit as well as total operating labour, utility cost and total production cost can be found in $[3,9,18,19]$.

Table 3: Estimation of total capital investment

\begin{tabular}{|c|c|c|c|}
\hline Item & $\begin{array}{c}\text { Cost Correction } \\
\text { factors } \\
\text { (Smith [13]) }\end{array}$ & $\begin{array}{c}\text { Amount }(\$) \\
\left(\times 1^{6}\right) \\
(\text { at } 2000)\end{array}$ & $\begin{array}{l}\text { Amount }(\$)\left(\times 10^{6}\right) \\
\text { (updated to } 2013)\end{array}$ \\
\hline Total delivered equipment cost factor $\boldsymbol{f}_{C_{E}^{o}}$ & 1.00 & 0.1190 & 0.1760 \\
\hline Purchased equipment installation $\boldsymbol{f}_{I N S}$ & 0.47 & 0.0560 & 0.0830 \\
\hline Instrumentation \& Controls(installed) $\boldsymbol{f}_{I \& C}$ & 0.36 & 0.0430 & 0.0630 \\
\hline Piping (installed) $\boldsymbol{f}_{\boldsymbol{P}}$ & 0.60 & 0.0710 & 0.1050 \\
\hline Electrical systems (installed) $\boldsymbol{f}_{\boldsymbol{E} \boldsymbol{S}}$ & 0.11 & 0.0130 & 0.0190 \\
\hline Buildings (including services) $\boldsymbol{f}_{\boldsymbol{B L D G}}$ & 0.18 & 0.0210 & 0.0320 \\
\hline Yard improvements $\boldsymbol{f}_{\boldsymbol{Y} \boldsymbol{I}}$ & 0.10 & 0.0120 & 0.0180 \\
\hline Service facilities (installed) $\boldsymbol{f}_{\boldsymbol{S F}}$ & 0.70 & 0.0830 & 0.1230 \\
\hline Engineering and supervision $\boldsymbol{f}_{\boldsymbol{E} \boldsymbol{n} \boldsymbol{g}}$ & 0.33 & 0.0390 & 0.0580 \\
\hline Construction expenses $f_{\text {CoNS }}$ & 0.41 & 0.0490 & 0.0720 \\
\hline Legal expenses $\boldsymbol{f}_{\boldsymbol{L E G}}$ & 0.04 & 0.0050 & 0.0070 \\
\hline Contractor's fee $\boldsymbol{f}_{C N T R C}$ & 0.22 & 0.0260 & 0.0390 \\
\hline Contingency $\boldsymbol{f}_{C N T G}$ & 0.44 & 0.0520 & 0.0770 \\
\hline Working Capital (WC) & 0.89 & 0.1060 & 0.1560 \\
\hline Total Capital Investment (TCl) (\$) & & 0.6940 & 1.0280 \\
\hline
\end{tabular}

The total bare module cost can be calculated with Eq.2 [24]. In this study, the expression is slightly modified, replacing the various cost factors with an overall correction factor $F_{B M}^{*}$, termed deterministic bare module factor, as:

$$
\begin{gathered}
C_{T C I}=\sum_{i} C_{E, i}^{o} \cdot\left(1+f_{p}\right) f_{M, i} f_{P, i} f_{T, i} F_{C E P C I} \\
+\left(f_{I N S T}+f_{I \& C}+f_{E S}+f_{B L D G}+f_{Y I}+f_{S F}+f_{E N G}+f_{C O N S}+f_{L E G}+f_{C N T R C}\right. \\
\left.+f_{C N T G}+f_{W C}+f_{S L V G}\right) \sum_{i} C_{E, i}^{o} \cdot f_{M, i} f_{P, i} f_{T, i .} F_{C E P C I} \\
\cong F_{B M}^{*} \sum_{i} C_{E, i}^{o} \cdot F_{C E P C I}
\end{gathered}
$$

The factor $F_{B M}^{*}$ is estimated with the values of the factors reported in Timmerhaus et al. [21] and is used in the subsequent stochastic analysis presented in this paper. The ratio of the 
Chemical Engineering Plant Cost Indices (CEPCI), $F_{C E P C I}$ covering the period between year 2000 and 2013 is given as:

$$
F_{C E P C I}=\left(\frac{C E P C I(2013)}{C E P C I(2000)}\right)
$$

The delivered cost of equipment $C_{E, i}^{o},(i=1,2, \ldots, k)$ corrected for capacity, material of construction, working pressure, temperature, inflation effect and transportation (delivery) can be obtained as:

$$
C_{E, i}^{o}=C_{E, i} \cdot f_{M, i} f_{P, i} f_{T, i} f_{D} F_{C E P C I}
$$

The individual equipment cost $\left(C_{E, i}\right)$ relative to a known similar facility (base case) is given as:

$$
C_{E, i}=C_{b, i}\left(\frac{Q_{E, i}}{Q_{b, i}}\right)^{q_{i}}
$$

where $C_{b, i}=$ Known base cost for similar equipment with capacity $Q_{b, i} ; Q_{E, i}=$ Capacity of equipment $i ; q_{i}=$ A constant depending on the type of equipment; $f_{M, i}, f_{P, i}$ and $f_{T, i}=$ Factors accounting for material of construction, working pressure and temperature, respectively; $f_{M, i}=1$ for equipment made of carbon steel, $f_{P, i}=1$ for equipment working at moderate pressure ( $P=0.5$ to 7 bar abs) and $f_{T, i}=1$ if the working temperature is near ambient $\left(T=0-100^{\circ} \mathrm{C}\right)[13]$. Note that, while $f_{M, i}$ for carbon steel is unity, for stainless steel (low grades), $f_{M, i}=2.4$. The factor $f_{D}$ accounts for the cost of delivery of equipment to the plant site, $f_{D}=1$ if the base equipment cost $\left(C_{b, i}\right)$ includes delivery charges.

On the other hand, a generic cost function in terms of Gross Profit $\left(P_{\text {gross }}\right)$ can be expressed as a difference between the Total revenue from products $\left(R_{T}\right)$ and the Total Investment Cost $\left(I_{T}\right)$ as: 


$$
P_{\text {gross }}=R_{T}-I_{T}
$$

The annual net profit (assuming an income tax rate of 50\%) is given as:

$$
P_{\text {net }}=0.5 P_{\text {gross }}
$$

A selection of the obtained deterministic financial measures is presented in Table 4. Note that these deterministic values may be used as reference points in deciding success/failure limits for the venture (this idea will be elaborated in the next section). Further details on equipment costing for this particular case study can be found in West et al. [9]. A major objective of this section is to provide a background against which the new stochastic process modelling framework (presented in the next section) can be illustrated.

Table 4: Summary of Economic Indicators

\begin{tabular}{lc}
\hline Economic Indicator & Deterministic value $\left(\times \mathbf{1 0}^{\mathbf{6}} \mathbf{)}\right.$ \\
\hline Total Capital Investment TCl, $(\$)$ & 1.08000 \\
Total Production Cost TPC, $(\$ / \boldsymbol{y r})$ & 8.44400 \\
Total revenue from Biodiesel and Glycerine $(\$ / \boldsymbol{y r})$ & 8.99300 \\
Net Profit After Tax NPT $(\$ / \boldsymbol{y r})$ & 0.29440 \\
Breakeven Price of Biodiesel $\boldsymbol{U}_{\boldsymbol{B}}^{*}(\$ /$ ton $)$ & 0.00109 \\
\hline
\end{tabular}

So far, impact of uncertainties arising from designs, random input/output variations, internal changes in the process due to chemical/physical operations and market forces have not been explicitly factored into the techno-economic evaluation which could lead to excess overdesign/specification, which is expensive. In addition, such deterministic approach has been shown to give limited insight into performance behaviour of process systems [25]. Stochastic techno-economic analysis can be used to model some of these sources of uncertainties taking into account their respective bounds and probability distributions, including the parametric interactions.

\subsection{STOCHASTIC ECONOMIC EVALUATION}

A major aim of this study is to develop a framework to model the uncertainty associated with some key variables, propagate them and investigate their cumulative impact on some economic decision-indicators such as the breakeven price of biodiesel $U_{B}^{*}(\$ /$ ton $)$, Total 
Capital Investment TCI (\$), Total Production Cost TPC (\$/yr), Total revenue from biodiesel \& Glycerine $(\$ / y r)$ and Net Profit after Tax NPT $(\$ / y r)$, etc. First, the biodiesel production process is modelled and simulated deterministically as described in the previous sections. This is followed by a number of performance modelling activities, shown in Fig.2.

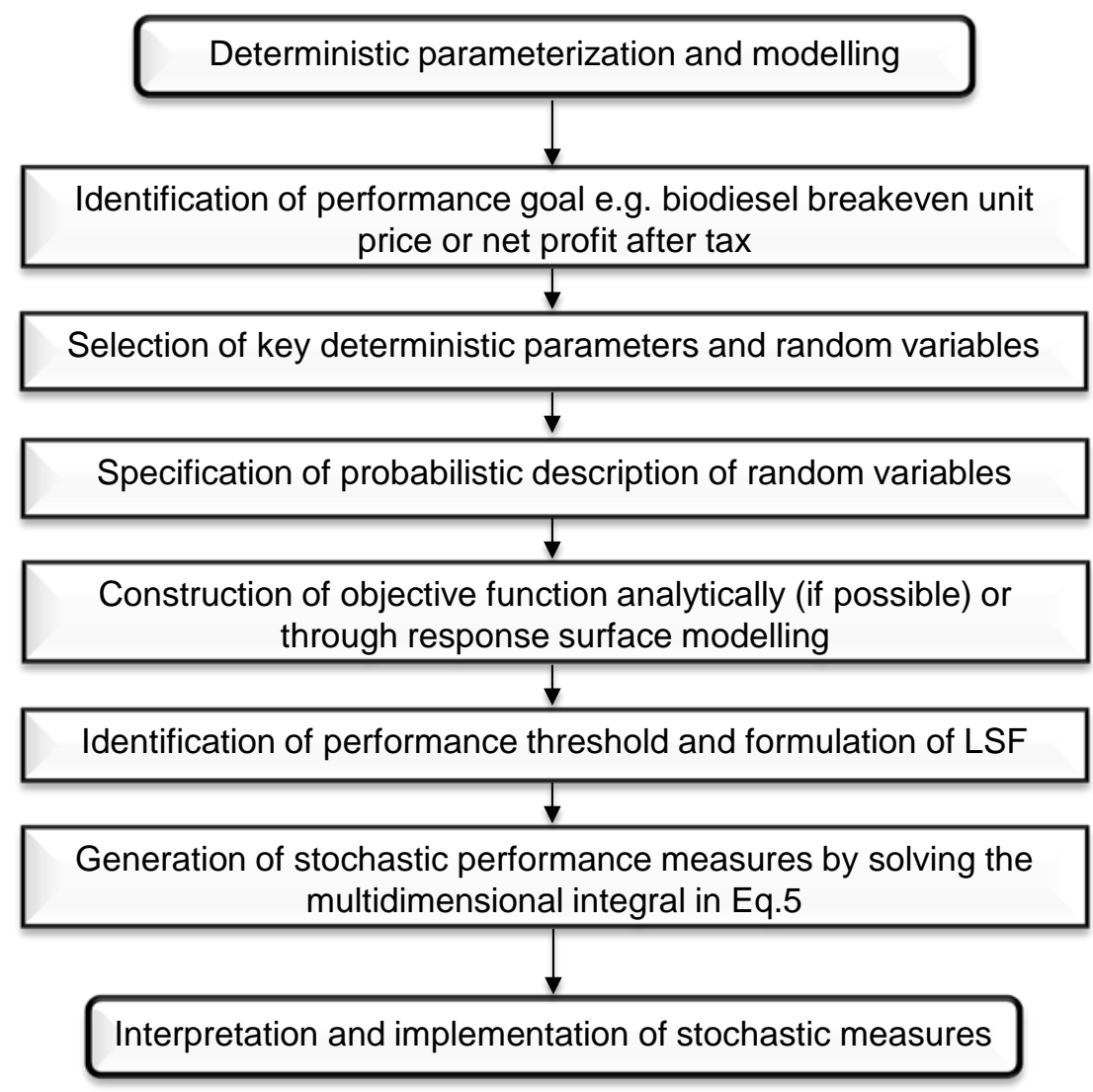

Figure 2: An approach for stochastic techno-economic assessment of biodiesel production plants

After constructing an objective function, a mathematical function, usually termed Limit State Function (LSF), is then defined to split the performance space into 'success' and 'failure' regions. Considering a system under uncertainty, we may for instance wish to determine the probability $\left(P_{f}\right)$, that the objective function $y(x)$ assumes a value equal to or less than a certain threshold $\varphi$, which can be a scalar or a function. This can be expressed as:

$$
P_{f}=P[y(x) \leq \varphi]=P[G(\underline{X}) \leq 0]
$$

In terms of the joint density function, the failure probability for the system may be defined as [26]: 


$$
P_{f}=\int_{G(\underline{X}) \leq 0} f_{\underline{X}}(\underline{x}) \cdot d \underline{x}
$$

where $G(\underline{X})$ is the LSF, $\underline{X}$ is the input vector and $f_{\underline{X}}($.$) is the joint probability density function.$ This approach to system performance characterization is inspired from the structural reliability principles [26-32]; a huge potential exists to optimise the techno-economic analysis of biodiesel production plants by extending these principles. Note that while structural reliability analysis is mainly concerned with the effects of random forces and mechanical properties on structural performance, the chemical process reliability analysis is focused on random process conditions (e.g. changes in reaction conditions, cost of raw materials, etc.) and their effects on product quantity/quality which eventually translate to profitability.

In the stochastic economic evaluation of biodiesel production plants, subject to the LSF, the chance of meeting some target thresholds, optimal operating conditions/design points, sensitivity of the target to each of the primary variables, reliability index and other important performance measures can be determined. In this work, solution of the multidimensional integral, given by Eq.9, is achieved by combining both FORM and MCS principles in order to gain wide range of stochastic performance measures.

\subsection{First Order Reliability Method (FORM)}

A major goal of FORM is to determine the most probable design/operating specifications, usually termed design point and the probability value/reliability index associated with it. After setting up the LSF, the basic variables $(\underline{X})$ are transformed (as depicted in Fig.3) from physical space to standard normal space, $\underline{Z}$ :

$$
Z_{i}=\frac{X_{i}-\mu_{X_{i}}}{\sigma_{X_{i}}}
$$

where $\mu_{X_{i}}$ and $\sigma_{X_{i}}$ are the first and second moments respectively and $X_{i}$ is a given realisation of the uncertain variable. It is worth noting that non Gaussian variables can also be handled through the normal tail transformation, as discussed in [32]. Such transformation is 
necessary in order to normalise the design space about the mean value of the objective function.

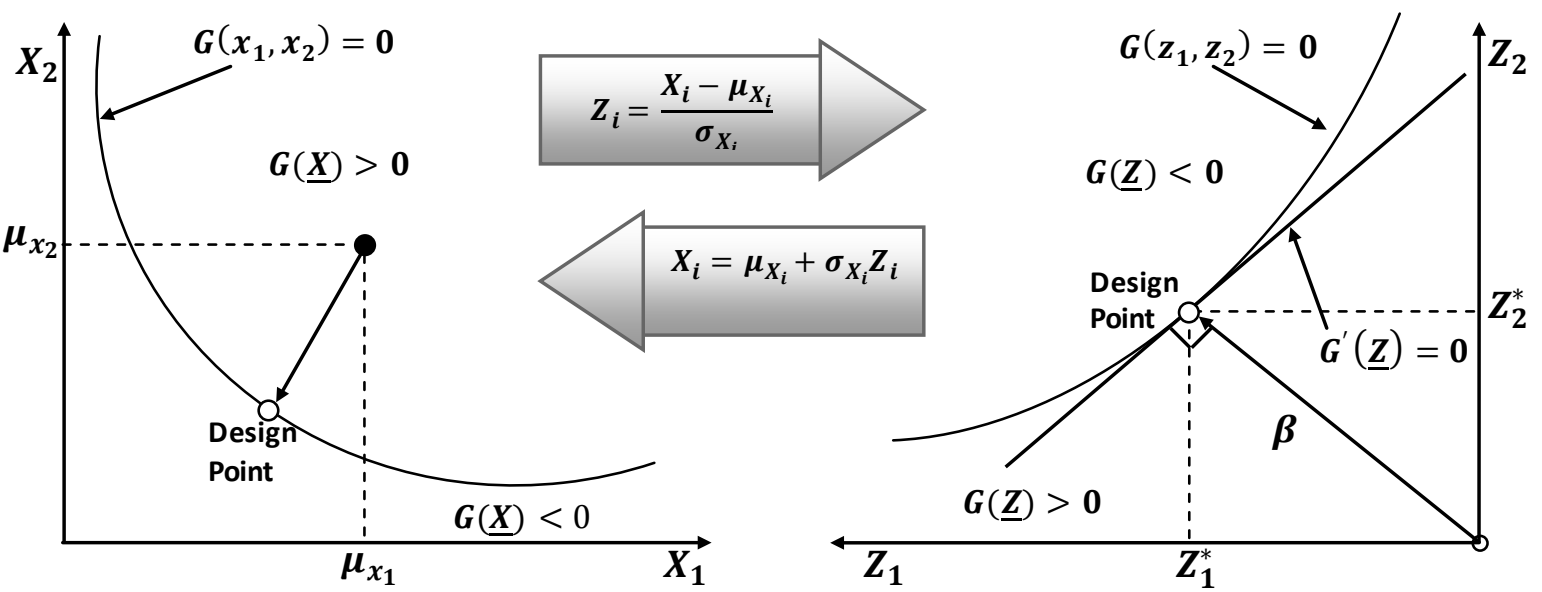

Figure 3: Failure surface transformation from physical $(X)$ to standard normal space $(Z)$ for a non-linear safety margin involving two independent Gaussian variables

Using first order Taylor series, the LSF, $G(\underline{X})$ is linearized about $z^{*}$ (which is initially unknown) as:

$$
G^{\prime}(Z) \approx G\left(z^{*}\right)+\nabla G\left(z^{*}\right)^{T} \cdot\left(Z-z^{*}\right)
$$

while:

$$
z^{*}=\operatorname{argmin}\left\{\frac{1}{2}\|z\|^{2} \mid G(z)=0\right\}
$$

A design point $Z^{*}$ to satisfy $G(\underline{Z}) \leq 0$ is then sought; improved Hasofer-Lind- RackwitzFiessler (iHLRF) algorithm can be used for this purpose $[27,28,33]$. In order to use iHLRF, an iteration counter $j$ is introduced into Eq.11 as:

$$
G^{\prime}(Z) \approx G\left(z_{j}^{*}\right)+\nabla G\left(z_{j}^{*}\right)^{T} \cdot\left(Z-z_{j}^{*}\right)
$$

The sensitivity indices $\alpha_{i}$ are defined by:

$$
\alpha_{i}=\frac{z_{i}^{*}}{\beta}
$$

These are the direction cosines of $\beta$ along the respective coordinates evaluated at $\underline{z}^{*}$ which give quantitative measures of the sensitivity of the system performance at the design point to 
changes in the basic variables. A simplified iHLRF search scheme [26] is given by Eq.15, evaluating iteratively until convergence, $(G(\underline{Z})=0$ or $\approx 0)$ is achieved.

$$
z_{i}^{*}=\alpha_{i}^{0} \times \frac{\left(\alpha_{j}^{0} z_{j}^{0}\right)^{T}-G\left(\underline{z}^{*^{\prime}}\right)}{\left(\alpha_{j}{ }^{2}\right)^{T}}
$$

The Hasofer-Lind $(\mathrm{H}-\mathrm{L})$ reliability index $\beta$ is given as.

$$
\beta=\left\{z_{i}^{*} \sqrt{\left[\left(\nabla G^{\prime}\left(Z_{i}\right)\right)^{2}\right]^{T}}\right\} / \nabla G^{\prime}\left(Z_{i}\right)
$$

where $\underline{z}^{*}$ is the point on the failure surface that minimizes $\beta$ in the standard normal space (coordinate of the point with the highest probability density), and $G^{\prime}$ is the linearized limit state function about $\underline{z}^{*}$ [29]. Essentially this is the length of the line segment between the origin and the 'failure' surface in the standard normal space $N(0,1)$. In practice, the higher the value of $\beta$, the less the probability of failure is set up to express failure probability). Also, it is to be noted that, depending on practical meaning of the chosen threshold, $G(\underline{X}) \leq 0$ can be set up to define various operating specifications and the associated failure/success probabilities. A number of solution techniques can be used to obtain performance measures from Eq.9 \&11. Detailed validation and application of the stochastic framework to individual process units was presented in Abubakar et al. [17].

\subsection{Monte Carlo Simulation (MCS)}

The multi-dimensional integral (Eq.9) can also be solved using MCS. First a counter function $I(x)$, defined by Eq.17, is introduced as shown in Eq.18 to change the integration domain to real space. Based on predefined probability distributions, samples are drawn and used to evaluate the $n$-dimensional integral subject to prescribed LSF and other boundary conditions.

$$
\begin{gathered}
I(x)= \begin{cases}1, & G(\underline{X}) \leq 0 \\
0, & G(\underline{X})>0\end{cases} \\
P_{f}=\int_{G(\underline{X}) \leq 0} I(x) f_{\underline{X}}(\underline{x}) d \underline{x} \cong \frac{1}{n_{T}} \sum_{i=1}^{n} I\left(x_{i}\right)
\end{gathered}
$$


Total sample size, $n_{T}$ and the indicator function counts can be used to estimate the probability $P_{f}$ of achieving (or missing) a desired design or performance target [32]. An estimate of the probability value is given by the ratio of the sum of the successful responses to the total number of responses. Note that the LSF is set up to constrain the objective function in order to realise a chosen performance target. Extensive literature on MCS method is given elsewhere [26, 30-32].

\subsection{Reliability based Techno-economic Analysis of a Biodiesel Plant}

A number of parameters affect the technical and financial performance of the biodiesel production plant. For simplicity, some of the variables are assumed to be well known, hence classified as deterministic parameters and the others are assumed to be stochastically varying (with given standard deviations, shown in Table 5). Note that classification like this could be subjective. With the exception of total delivered equipment cost, which is modelled by a uniform distribution, the remaining random variables are assumed to be governed by a Gaussian distribution.

Input/output concentrations that are not of economic significance have been ignored in the mass balance. The total delivered equipment cost $C_{E}^{o}$ (modelled by a uniform distribution) has a lower bound of $\$ 89003$ and an upper bound of $\$ 148338$ corresponding to $\pm 25 \%$ error limits respectively. The variables: Total production cost factor $\left(F_{T P C}\right)$, Bare module factor $\left(F_{B M}\right)$ and Total capital investment factor $\left(F_{T C I}\right)$ are assigned a Coefficient of Variation (CoV) of $10 \%$ whereas a CoV of about $8 \%$ is ascribed to each of the mass fractions.

Analytically, a simplified cost function for the biodiesel plant in terms of the gross profit takes the following form:

$$
\begin{aligned}
\text { Gross Profit }= & (\text { Income from }: \text { Biodiesel }+ \text { Glycerine }+ \text { Unreacted WCO }) \\
& -[\text { Start up Cost }+ \text { Depreciation }+ \text { Total Production Cost })
\end{aligned}
$$


Table 5: List of parameters: deterministic and stochastic

\begin{tabular}{|c|c|c|c|}
\hline S/N & Parameter & $\begin{array}{l}\text { Mean/Nominal } \\
\text { Value }\end{array}$ & $\begin{array}{l}\text { Standard } \\
\text { deviation }\end{array}$ \\
\hline 1 & Average depreciation factor $F_{D i s c}$ & 1.2770 & - \\
\hline 2 & Equipment cost updating factor $F_{\mathrm{CEPCI}}(\mathrm{CEPCI})$ & 1.4810 & - \\
\hline 3 & Factor accounting for start-up cost $(10 \%$ of $\mathrm{FCl}), F_{\text {stup }}$ & 0.1000 & - \\
\hline 4 & Consumer price index CPI (covering the period 2000-2013) & 1.3500 & - \\
\hline 5 & Unit price of Glycerine $U_{G},(\$ /$ ton $)$ & 700.00 & - \\
\hline 6 & Unit price of methanol $U_{M},(\$ /$ ton $)$ & 211.00 & - \\
\hline 7 & Unit price of waste cooking oil $U_{W o},(\$ /$ ton $)$ & 400.00 & - \\
\hline 8 & Factor accounting for cost of delivery $f_{D e l}$ & 1.0000 & - \\
\hline 9 & Capital/construction cost inflation rate $r(\%)$ & 0.0200 & - \\
\hline 10 & Production/raw materials/product cost inflation rate $p(\%)$ & 0.0000 & - \\
\hline 11 & Mass flowrate in biodiesel product stream $m_{B},(\mathrm{~kg} / \mathrm{hr})$ & 989.60 & - \\
\hline 12 & Mass flowrate in glycerine product stream $m_{G},(\mathrm{~kg} / \mathrm{hr})$ & 100.40 & - \\
\hline 13 & Mass flowrate in methanol feed stream $m_{M-i n},(\mathrm{~kg} / \mathrm{hr})$ & 108.30 & - \\
\hline 14 & Mass flowrate in unreacted WCO product stream $m_{U W O},(\mathrm{~kg} / \mathrm{hr})$ & 59.800 & - \\
\hline 15 & Mass flowrate in WCO feed stream $m_{W o-i n},(\mathrm{~kg} / \mathrm{hr})$ & 1050.0 & - \\
\hline 16 & Plant life span $n(y r s)$ & 20.000 & - \\
\hline 17 & Upstream plant time per year $t(h r)$ & 7920.0 & - \\
\hline 18 & Total Delivered Equipment Cost $C_{E}^{o}$, (\$) & 118670 & 17125.0 \\
\hline 19 & Glycerine in product stream4 $x_{4}^{G},(\%)$ & 0.9625 & 0.0674 \\
\hline 20 & Biodiesel in product strem $1 x_{1}^{B},(\%)$ & 0.9800 & 0.0686 \\
\hline 21 & Biodiesel in product strem2 $x_{2}^{B},(\%)$ & 0.0165 & 0.0012 \\
\hline 22 & Unreacted waste cooking oil in product stream2 $x_{2}^{U W O},(\%)$ & 0.9835 & 0.0492 \\
\hline 23 & Methanol in Feed stream $x_{i n}^{M},(\%)$ & 0.9750 & 0.0683 \\
\hline 24 & Waster cooking oil in feed stream $x_{i n}^{W C O},(\%)$ & 0.9500 & 0.0665 \\
\hline 25 & Total Production Cost factor $F_{T P C}$ & 2.0318 & 0.2032 \\
\hline 26 & Bare module factor $F_{B M}$ & 4.9600 & 0.4960 \\
\hline 27 & Total Capital Investment factor $F_{T C I}$ & 5.8500 & 0.5850 \\
\hline
\end{tabular}

A straight-line depreciation and start-up cost are assumed to be at $10 \%$ of Fixed Capital Investment $(\mathrm{FCl})$, i.e. depreciation factor $f_{\text {Dep }}=0.1$ and start-up cost factor $f_{\text {St.up }}=0.1$. The factors $F_{T C I}, F_{T P C}$ and $F_{B M}$ are computed based on the individual factors given in Timmerhaus et al. [21] and $F_{C E P C I}$ is the cost updating factor, which is the ratio of the CEPCI covering the period between year 2000 and 2013. Assuming 100\% (optimistic) plant capacity utilization, the gross annual profit, from first principles, can be obtained as:

$$
\begin{aligned}
P_{\text {gross }}=\left(\left(x_{2}^{B} m^{B}\right.\right. & \left.\left.+x_{3}^{B} m^{U W O}\right) t U_{B}+x_{1}^{G} m^{G} t U_{G}\right) \\
& -\left[f_{\text {st.up }} \cdot F_{B M} \cdot \sum_{i} f_{D} \cdot C_{E, i}^{o} \cdot F_{C E P C I}+f_{D e p} \cdot F_{B M} \cdot \sum_{i} f_{D} \cdot C_{E, i}^{o} \cdot F_{C E P C I}\right. \\
& \left.+F_{T P C} \cdot\left(x_{i n}^{W O} m_{i n}^{W O} \cdot U_{w o}+x_{i n}^{M} m_{i n}^{M} \cdot U_{M}\right) t\right]+x_{3}^{U W O} m^{U W O} t U_{w o}
\end{aligned}
$$


where $x, m=$ Mass fraction and mass flowrate; $B, G, M, W C O$ and $U W O$ refer to biodiesel, glycerine, methanol, waste oil and unreacted waste oil respectively; $t=$ Upstream time per year $(t=330$ days $\times 24 h r s=7920 h r s) ; U_{B}, U_{G}=$ Price per unit of biodiesel and glycerine respectively $(\$ /$ ton $)$ and $f_{\text {Dep }}=$ Average depreciation factor. Note that the start-up cost is a one off disbursement hence discounted only once; discounting against inflation and time value of money, the gross profit can be obtained as:

$$
\begin{aligned}
P_{\text {gross }}=\left(\left(x_{2}^{B} m^{B}\right.\right. & \left.\left.+x_{3}^{B} m^{U W O}\right) t U_{B}+x_{1}^{G} m^{G} t U_{G}\right) \cdot(1+p)^{n+2} \\
& -\left[\left(f_{\text {St.up }} \cdot F_{B M .}(1+r)^{n+2}+f_{\text {Dep }} \cdot F_{B M .}(1+r)^{n+2}\right) \cdot \sum_{i} f_{D} \cdot C_{E, i}^{o} \cdot F_{C E P C I}\right. \\
& \left.+F_{T P C} \cdot\left(x_{i n}^{W O} m_{\text {in }}^{W O} \cdot U_{w o}+x_{i n}^{M} m_{i n}^{M} \cdot U_{M}\right) t \cdot(1+r)^{n+2}\right] \\
& +x_{3}^{U W O} m^{U W O} t U_{w o} \cdot(1+p)^{n+2}
\end{aligned}
$$

The product inflation rate $p$ is assumed to be zero and the construction as well as total production cost inflation rates $r$ are assumed to be 2\% [21]. For the purpose of this study, expected value of the discounting factor is computed as:

$$
F_{\text {Disc }}=\sum_{n=0}^{20}(1+0.02)^{n+2} / 20=1.2774
$$

The total sales computed when the profit $P_{\text {net }}=P_{\text {gross }}=0$, can be used to estimate the breakeven unit price of the biodiesel, from Eq.21, this can be expressed as:

$U_{B}^{*}$

$$
\begin{aligned}
& {\left[\left(f_{\text {St.up }} \cdot F_{B M .}(1+r)^{n+2}+f_{\text {Dep }} \cdot F_{B M}(1+r)^{n+2}\right) \cdot \sum_{i} f_{D} \cdot C_{E, i}^{o} \cdot F_{C E P C I}+\right.} \\
& =\frac{\left.F_{T P C} \cdot\left(x_{i n}^{W O} m_{i n}^{W O} \cdot U_{w o}+x_{i n}^{M} m_{i n}^{M} \cdot U_{M}\right) t \cdot(1+r)^{n+2}-x_{3}^{U W O} m^{U W O} t U_{w o} \cdot(1+p)^{n+2}-\left(x_{1}^{G} m^{G} t U_{G}\right)\right]}{\left(x_{2}^{B} m^{B}+x_{3}^{B} m^{U W O}\right) t(1+p)^{n+2}}
\end{aligned}
$$

Among others, the net profit after tax $(\$)$ and expected biodiesel breakeven price $(\$ /$ ton $)$ across the life of the plant (20yrs) will be modelled here based on both MCS and FORM. Given a target minimum acceptable net profit $P_{\min }$ and a threshold breakeven unit cost of biodiesel $U_{B_{\max }}^{*}$, from Eqs.8 \& 20-23, probability of recording a net after tax profit greater than $P_{\min }$ can be expressed as:

$$
P_{f P}=P\left[\left(P_{\text {net }} \geq P_{\text {min }}\right) \$ / \mathrm{yr}\right]
$$


In addition, the market condition is also assumed to be stable in terms of supply and demand throughout the life of the plant. In the presence of techno-economic uncertainties, the chance that the breakeven prices of biodiesel would have to be greater than $U_{B \min }^{*}(\$ /$ ton$)$ is given by:

$$
P_{f B}=P\left[\left(U_{B}^{*} \geq U_{B \max }^{*}\right) \$ / \text { ton }\right]
$$

Therefore, instead of quoting a single deterministic value for an economic indicator, which in reality is uncertain, it is possible to determine the most credible range and distribution for any economic indicator of interest. It is also possible to assess specific values within a range in probabilistic terms. Furthermore, most probable design/operation specifications to achieve a given performance target including sensitivity indices can also be evaluated; some possible examples are presented in Tables $6(\mathrm{a} \& \mathrm{~b})$ and Figs. 4 - 5 .

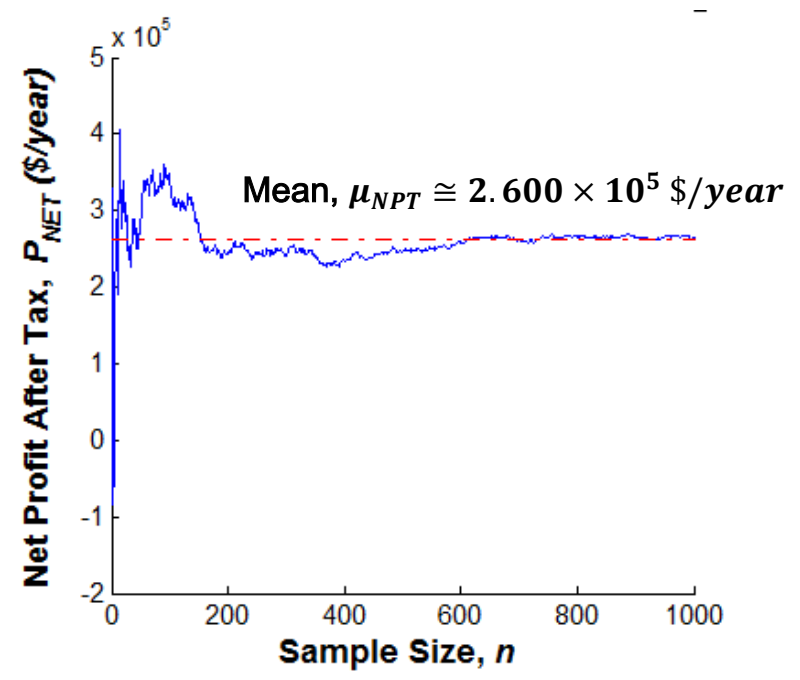

Figure 4: Average Net Profit after Tax per annum

For instance, from Table $6(\mathrm{a})$, it can be seen that the net after tax profit has a range $[a, b]_{N P T} \cong\left[-2.27 \times 10^{6}, 2.47 \times 10^{6}\right] \$ / y r$ and the chance of recording profit that is equal to or greater than $1.2 \times 10^{6} \$ / y r$ is about $5 \%$ as obtained through both FORM and MCS analysis. Based on the form of the LSF, the reliability index $\beta$ in this context gives a measure of possibility of achieving the target i.e. having $N P T$ equal to or greater than $1.2 \times 10^{6} \$ / y r$, 
the bigger the probability value the smaller the $\beta$. Note that this example is relevant to those cases where smaller $\beta$ value is desired.

The distribution of NPT about the mean values is shown in Fig.4. It can be seen that the margin is slightly above zero with probability of running the biodiesel plant at loss $P[(N P T \leq$ $0) \$ / y r] \cong 29 \%$ and probability of recording profit above $1.50 \times 10^{6} \$ / y r$, i.e. $P[(N P T \geq$ $\left.\left.1.50 \times 10^{6}\right) \$ / y r\right]=1-0.98 \cong 2 \%$.

On the other hand, it can be seen that the breakeven price of biodiesel appears to be best fitted by a lognormal distribution followed by Gaussian and Weibull distributions as shown in Fig. 5(a). The possible variation around a deterministic consideration can also be seen in this figure. It is to be noted that the analysis started with the assumption of only two types of distributions- Gaussian and uniform. A cumulative distribution curve based on the lognormal fit is shown in Fig. 5(b), probability values associated with specific or a range of biodiesel breakeven prices can be estimated from such distribution plots. For instance, in the presence of the kind of uncertainties described earlier, probability that the breakeven price of biodiesel is equal to or less than $900 \$ /$ ton, i.e. $P\left[\left(U_{B}^{*} \leq 900\right) \$ /\right.$ ton $] \cong 14 \%$, as indicated in Fig.5(b); it can also be seen that the chance that the price lies between 900 and $1200 \$ /$ ton i.e. $P\left[\left(900<U_{B}^{*}<1200\right) \$ /\right.$ ton $] \cong 70 \%$. Metrics, including sample study thresholds and the probability values for a number of other economic indicators are given in Table 7 . It is to be noted that these study thresholds are used for illustrative purposes only; they can be modified, depending on economics, safety and reliability constraints. 

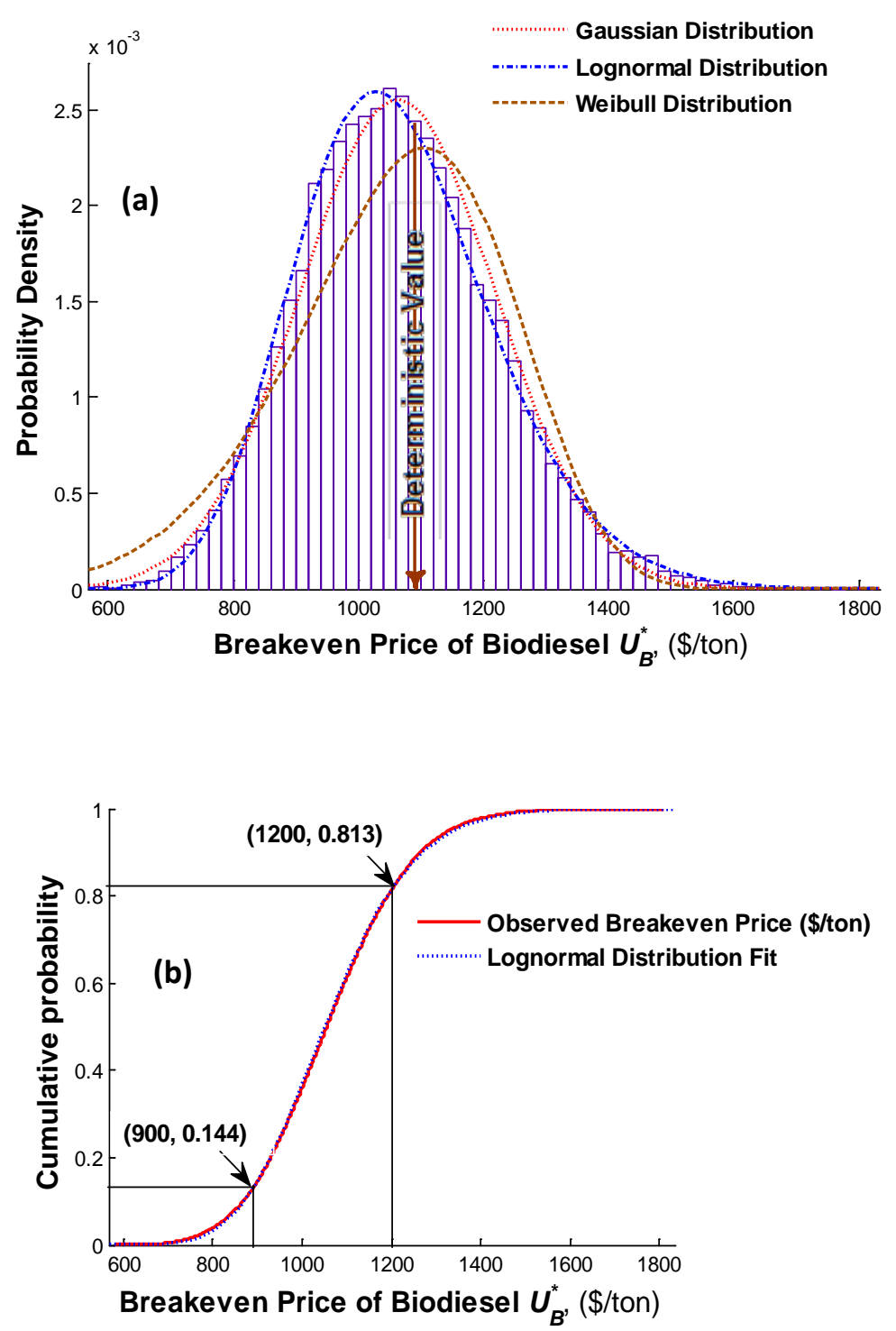

Figure 5 (a \& b): Expected distribution of breakeven price of biodiesel given the uncertainties in both design and Market forces 
Table 6 (a \& b): Sample probabilistic assessment of a biodiesel production plant

\begin{tabular}{|c|c|c|c|}
\hline \multicolumn{4}{|c|}{ (a) After Tax Net Profit } \\
\hline \multirow{3}{*}{\multicolumn{3}{|c|}{$\begin{array}{c}\text { FORM Analysis } \\
P\left[\left(N P T \geq 1.20 \times 10^{6}\right) \$ / y r\right]=0.0514 \\
\text { H-L Index, } \beta=1.630\end{array}$}} & Monte Carlo Simulation Analysis \\
\hline & & & $\boldsymbol{P}\left[\left(\boldsymbol{N P T} \geq \mathbf{1 . 2 0} \times 10^{6}\right) \$ / \boldsymbol{y r}\right]=0.0535$ \\
\hline & & & H-L Index, $\beta=1.611$ \\
\hline Parameter & $\begin{array}{l}\text { Design/Op. } \\
\text { Spec. }\left(\underline{X}^{*}\right)\end{array}$ & $\alpha_{i}$ & \\
\hline$F_{B M}(-)$ & 4.959 & -0.002 & $\mu_{N P T}=2.54 \times 10^{5} \$ / y r$ \\
\hline $\boldsymbol{F}_{T P C}(-)$ & 1.791 & -0.726 & $\sigma_{N P T}=6.00 \times 10^{5} \$ / y r$ \\
\hline$C_{E}^{o} \quad(\$)$ & $1.185 \times 10^{5}$ & -0.004 & {$[a, b]_{N P T} \cong\left[-2.27 \times 10^{6}, 2.47 \times 10^{6}\right] \$ / y r$} \\
\hline$x_{1}^{B} \quad(\%)$ & 1.00 & 0.521 & \\
\hline$x_{2}^{B} \quad(\%)$ & 0.017 & $5.510 \times 10^{-4}$ & \\
\hline$x_{4}^{G} \quad(\%)$ & 0.966 & 0.033 & \\
\hline$x_{i n}^{M}(\%)$ & 0.972 & -0.025 & \\
\hline$x_{2}^{U W O}(\%)$ & 0.984 & 0.008 & \\
\hline$x_{i n}^{W C O}(\%)$ & 0.902 & -0.446 & \\
\hline
\end{tabular}

\section{(b) Breakeven Price of biodiesel}

\begin{tabular}{|c|c|c|c|}
\hline \multicolumn{3}{|c|}{$\begin{array}{c}\text { FORM Analysis } \\
P\left[\left(U_{B}^{*} \geq \mathbf{1 3 0 0}\right) \$ / \text { ton }\right]=0.0738 \\
\text { H-L Index, } \beta=1.4500\end{array}$} & \multirow[t]{2}{*}{$\begin{array}{c}\text { Monte Carlo Simulation Analysis } \\
\boldsymbol{P}\left[\left(\boldsymbol{U}_{\boldsymbol{B}}^{*} \geq \mathbf{1 3 0 0}\right) \$ / \text { ton }\right]=0.0735 \\
\mathbf{H}-\mathbf{L} \text { Index, } \beta=1.4502\end{array}$} \\
\hline Parameter & $\begin{array}{l}\text { Design/Op. } \\
\text { Spec. }\left(\underline{X}^{*}\right)\end{array}$ & $\alpha_{i}$ & \\
\hline$F_{B M}(-)$ & 4.971 & 0.016 & $\mu_{U_{B}^{*}}=1060 \$ /$ ton \\
\hline$F_{T P C}(-)$ & 2.235 & 0.693 & $\sigma_{U_{B}^{*}}=156$ \\
\hline$C_{E}^{o} \quad(\$)$ & $1.19 \times 10^{5}$ & 0.031 & {$[a, b]_{U_{B}^{*}} \cong[584,1808] \$ /$ ton } \\
\hline$x_{1}^{B} \quad(\%)$ & 0.927 & -0.534 & \\
\hline$x_{2}^{B} \quad(\%)$ & 0.016 & $-5.642 \times 10^{-4}$ & \\
\hline$x_{4}^{G} \quad(\%)$ & 0.960 & -0.029 & \\
\hline$x_{i n}^{M}(\%)$ & 0.978 & 0.027 & \\
\hline$x_{2}^{U W O}(\%)$ & 0.983 & -0.007 & \\
\hline$x_{i n}^{W C o}(\%)$ & 0.996 & 0.482 & \\
\hline
\end{tabular}


Table 7: MCS Results Reflecting Viability of a Biodiesel Production Plant under both Technical and Economic Uncertainties

\begin{tabular}{lcccc}
\hline \multicolumn{1}{c}{ Economic Indicator, $\boldsymbol{y}(\boldsymbol{x})$} & Mean & Std & $\begin{array}{c}\text { Study } \\
\text { Threshold, } \boldsymbol{\varphi}\end{array}$ & $\begin{array}{c}\text { Probability of } \\
\text { Exceeding } \boldsymbol{\varphi}: \\
\boldsymbol{P}_{\boldsymbol{E}}=\boldsymbol{P}[\boldsymbol{y}(\boldsymbol{x}) \geq \boldsymbol{\varphi}]\end{array}$ \\
\hline $\begin{array}{l}\text { Total Capital Investment TCI, } \\
(\$)\end{array}$ & $1.0701 \times 10^{6}$ & $1.8903 \times 10^{5}$ & $1.5 \times 10^{6}$ & 0.0121 \\
$\begin{array}{l}\text { Total Production Cost TPC, } \\
(\$ / \boldsymbol{y} \boldsymbol{r})\end{array}$ & $8.6551 \times 10^{6}$ & $1.0408 \times 10^{6}$ & $12.0 \times 10^{6}$ & 0.0011 \\
$\begin{array}{l}\text { Total revenue from Biodiesel } \\
\text { and Glycerine, RBG }(\$ / y \boldsymbol{r})\end{array}$ & $8.9974 \times 10^{6}$ & $5.9275 \times 10^{5}$ & $11.0 \times 10^{6}$ & $5.5000 \times 10^{-4}$ \\
$\begin{array}{l}\text { Net Profit After Tax NPT } \\
(\$ / y \boldsymbol{r})\end{array}$ & $2.5396 \times 10^{5}$ & $6.0066 \times 10^{5}$ & $1.2 \times 10^{6}$ & 0.0535 \\
$\begin{array}{l}\text { Breakeven Price of } \\
\text { Biodiesel, } \boldsymbol{U}_{\boldsymbol{B}}^{*}(\$ / \text { ton })\end{array}$ & $1.0629 \times 10^{3}$ & 156.2893 & 1300 & 0.0735 \\
\hline
\end{tabular}

\subsubsection{Sensitivity of performance target to basic variables}

Based on the sensitivity indices $\left(\boldsymbol{\alpha}_{i}\right)$ as shown in Tables $6(\mathrm{a} \& \mathrm{~b})$, it is possible to rank the basic variables in order of their impact on a given economic indicator. Also, it can be seen that a number of random variables influence profitability of the biodiesel production plant in different ways as indicated by the magnitude and directions ( \pm signs) of the sensitivity indices. As a specific example, the breakeven price of the biodiesel is most sensitive to TPC factor $F_{T P C}$ with a sensitivity index of +0.69 , followed by biodiesel mass fraction in P.Stream1 (shown in Fig.1) $x_{1}^{B}$ with sensitivity index of -0.534 and so on (as shown in Table $6(\mathrm{~b})$ ). Hence, with reference to the limit state function $U_{B}^{*} \geq 1300 \$ /$ ton, the plus sign associated with $F_{T P C}$ suggests that higher TPC raises the breakeven unit cost of biodiesel whereas the negative sign associated with $x_{1}^{B}$ suggests that lower biodiesel mass fraction in P.Stream1 leads to higher breakeven price, which confirms the usual expectation. Also, based on the form of the limit state statement and the practical significance of the economic indicators $\left(U_{B}^{*}\right)$, it implies that lower probability value (hence higher Hasofer-Lind reliability index $\beta$ ) is desired in this context. Compare this to the case of NPT in which lower $\beta$ is required even though the limit state functions in both cases have the same form $(P[y(x) \geq \varphi])$. This is 
because, in practice, the profit (NPT) needs to be maximized whereas a major target is to minimise the breakeven cost $\left(U_{B}^{*}\right)$. Consequently, if having a breakeven price higher than $1300 \$ /$ ton is considered as failure, then going by the directions ( \pm signs) associated with the sensitivity indices presented in Table $6(\mathrm{~b})$, higher values of $F_{T P C}$ (or lower values of $x_{1}^{B}$ ) increase failure probability, hence, lowering the reliability index.

\subsubsection{Stochastic economic indicators}

In the presence of various sources of uncertainties and assuming that the biodiesel market remains stable, the study is also able to provide potential ranges for various economic indicators including a probabilistic scale that can be used to assess specific threshold values or intervals, as illustrated in Table 7 and elsewhere in this paper. For instance, the study further confirms that the NPT from the biodiesel plant is only marginal with a mean of $2.54 \times 10^{5} \$ / y r$, and is likely to take on values in the interval $\left[-2.27 \times 10^{6}, 2.47 \times 10^{6} \$ / y r\right]$ during the life time of the plant; while probability of sustaining a negative margin for this particular plant is found to be about $30 \%$. It may also be seen that total revenue from the sales of both biodiesel and glycerine has an average value of $8.9974 \times 10^{6} \$ / y r$; it was also found that this economic indicator may lie anywhere between $6.49 \times 10^{6}$ and $1.13 \times 10^{7} \$ / y r$. Assuming that the inflation rate is constant and that market demand and biodiesel production are in equilibrium throughout the life of the plant, probability of recording a total revenue greater than $11.0 \times 10^{6} \$ / y r$ is estimated at $5.50 \times 10^{-4}$. Similar details on other economic indicators such as the total capital investment, production cost and revenue generation are shown in Table 7. Specific values (study thresholds) have been selected in each case and assessed in terms of probability. The first moments obtained from this stochastic analysis are in good agreement with previously published nominal values. However, besides the deterministic options, stochastic techno-economic analysis offers a wide range of additional performance measures. Such measures can be used to support stakeholders such as the process engineers, prospective investors and various government agencies as they set out to make critical decisions. 
Finally, in addition to the cost drivers considered in this paper, a number of other factors have considerable effect on economic viability of biodiesel production; these include, but not limited to, plant capacity, carbon credit and tax regime/government policies. Deterministic treatment of these issues was presented in [20,34,35], and the proposed stochastic approach can be applied to deduce them stochastically.

\subsection{CONCLUSIONS}

Using the proposed stochastic techno-economic analysis method, it is possible to model and characterise the performance of biodiesel production plants under uncertainty in an efficient way. A number of performance measures including probability of success/failure, reliability index, probabilistic design/operational specifications, sensitivity indices and economic indicators can be evaluated to support practical design and management decisions. Unlike the traditional deterministic analyses, the presented stochastic approach is able to account for performance nonlinearity, non-Gaussian behaviour and low probability events (which could be of high consequence). Stochastic process performance modelling does not only increase the prospect for early flaw detection, it also makes it possible to assess the potency of various design/operational specifications in a probabilistic framework; providing deeper insights into performance behaviour of process systems. It is to be noted that all the economic indicators reported in this paper are based on a fixed-capacity $(\sim 7800$ ton $/ y r)$, heterogonous catalysed biodiesel production plant using WCO and methanol as feedstock. Although this paper focuses on biodiesel production plants, the proposed stochastic approach is also appropriate for techno-economic analysis of any typical engineering process system.

\section{ACKNOWLEDGMENTS}

The authors wish to gratefully acknowledge the financial support granted by Petroleum Technology Development Fund (PTDF), Nigeria. Sriramula's work within the Lloyd's Register Foundation Centre for Safety and Reliability Engineering at the University of Aberdeen is supported by Lloyd's Register Foundation. The Foundation helps to protect life and property 
by supporting engineering-related education, public engagement and the application of research.

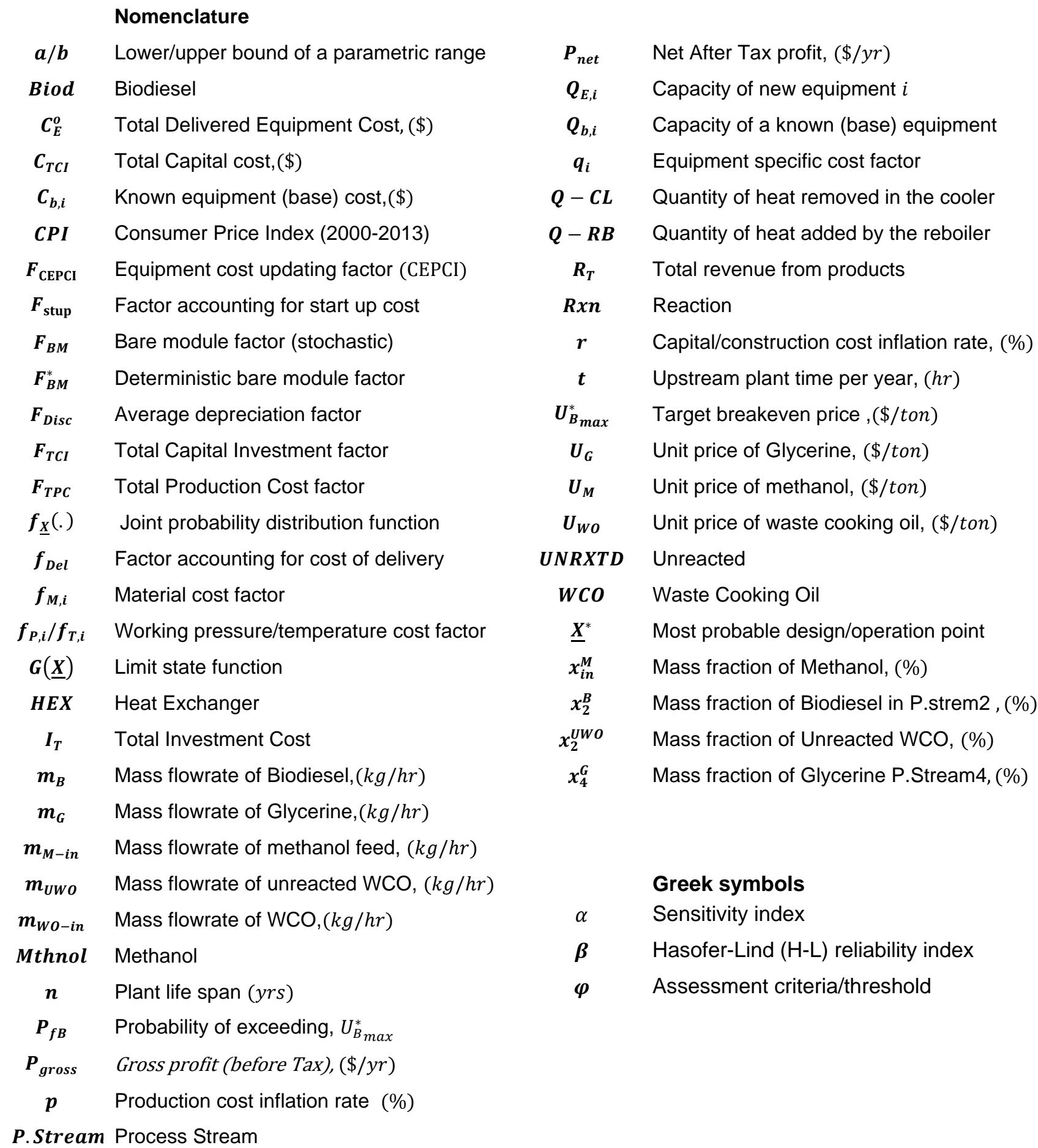




\section{REFERENCES[}

1] Yusuf NNAN, Kamarudin SK, Yaakub Z. Overview on the current trends in biodiesel production. Energy Conversion and Management 2011;52:2741-51.

[2] Phan AN, Phan TM. Biodiesel production from waste cooking oils. Fuel 2008;87:3490-6.

[3] Yaakob Z, Mohammad M, Alherbawi M, Alam Z, Sopian K. Overview of the production of biodiesel from Waste cooking oil. Renewable and Sustainable Energy Reviews 2013;18:184-93.

[4] Abo El-Enin SA, Attia NK, El-lbiari NN, El-Diwani GI, El-Khatib KM. In-situ transesterification of rapeseed and cost indicators for biodiesel production. Renewable and Sustainable Energy Reviews 2013;18:471-7.

[5] Atabani AE, Mahlia TMI, Anjum Badruddin I, Masjuki HH, Chong WT, Lee KT. Investigation of physical and chemical properties of potential edible and non-edible feedstocks for biodiesel production, a comparative analysis. Renewable and Sustainable Energy Reviews 2013;21:749-55.

[6] Huynh L, Kasim NS, Ju Y. Chapter 16 - Biodiesel Production from Waste Oils. In: Ashok Pandey A2Christian Larroche A2Steven C. Ricke A2Claude-Gilles Dussap and Edgard GnansounouA2 Ashok Pandey, Christian Larroche, Steven C. Ricke,Claude-Gilles Dussap, Edgard Gnansounou, editors. Biofuels, Amsterdam: Academic Press; 2011, p. 375-396.

[7] Zhang Y, Dubé MA, McLean DD, Kates M. Biodiesel production from waste cooking oil: 1. Process design and technological assessment. Bioresour Technol 2003;89:1-16.

[8] Zhang Y, Dubé MA, McLean DD, Kates M. Biodiesel production from waste cooking oil: 2. Economic assessment and sensitivity analysis. Bioresour Technol 2003;90:229-40.

[9] West AH, Posarac D, Ellis N. Assessment of four biodiesel production processes using HYSYS.Plant. Bioresour Technol 2008;99:6587-601.

[10] Encinar JM, González JF, Rodríguez-Reinares A. Ethanolysis of used frying oil. Biodiesel preparation and characterization. Fuel Process Technol 2007;88:513-22.

[11] van Kasteren JMN, Nisworo AP. A process model to estimate the cost of industrial scale biodiesel production from waste cooking oil by supercritical transesterification. Resour Conserv Recycling 2007;50:442-58.

[12] Turton R, Bailie RC, Whiting WB, Shaeiwitz JA. Analysis, synthesis and design of chemical processes. : Pearson Education, 2008.

[13] Robin Smith. Chemical Process Design and Integration. 2nd ed. The Atrium, Chichester, England: John Wiley \& Sons Ltd, 2005.

[14] Thompson W, Meyer S, Green T. The U.S. biodiesel use mandate and biodiesel feedstock markets. Biomass Bioenergy 2010;34:883-9.

[15] Annie Francie K, Jean-Pierre K, Pierre D, Victor S, Vladimir P. Stochastic optimal control of manufacturing systems under production-dependent failure rates. Int J Prod Econ 2014;150:174-87.

[16] Park C, Lee H. Performance evaluation of a multi-product CONWIP assembly system with correlated external demands. Int J Prod Econ 2013;144:334-44.

[17] Abubakar U, Sriramula S, Renton NC. A hybrid method for stochastic performance modelling and optimization of chemical engineering processes. Chemical Engineering Communications (in press). 
[18] Taylor B, Xiao N, Sikorski J, Yong M, Harris T, Helme T et al. Techno-economic assessment of carbon-negative algal biodiesel for transport solutions. Appl Energy 2013;106:262-74.

[19] Vlysidis A, Binns M, Webb C, Theodoropoulos C. A techno-economic analysis of biodiesel biorefineries: Assessment of integrated designs for the co-production of fuels and chemicals. Energy 2011;36:4671-83.

[20] Torres CM, Ríos SD, Torras C, Salvadó J, Mateo-Sanz JM, Jiménez L. Sustainability analysis of biodiesel production from Cynara Cardunculus crop. Fuel 2013;111:535-42.

[21] Timmerhaus KD, Peters MS, West R. Plant design and economics for chemical engineers. Chemical Engineering Series 1991.

[22] BLS- Consumer Price Index, Available at: www.bls.gov/cpi/home.htm\#data [September, 2014].

[23] CEPCl, Chemical Engineering Plant Cost Index, Available at: www.che.com/pci [September, 2014].

[24] Smith.G. J, Wilding. W. V, Oscarson J. L., and Rowley. R. L. CORRELATION OF LIQUID VISCOSITY AT THE NORMALBOILING POINT. 2003.

[25] Jensen HA, Maturana S. A possibilistic decision support system for imprecise mathematical programming problems. Int J Prod Econ 2002;77:145-58.

[26] Thoft-Christensen P, Baker MJ. Structural Reliability Theory and Its Applications. : SpringerVerlag, 1982.

[27] Haukaas T, Kiureghian AD. Strategies for finding the design point in non-linear finite element reliability analysis. Prob Eng Mech 2006;21:133-47.

[28] Liu P, Der Kiureghian A. Optimization algorithms for structural reliability. Struct Saf 1991;9:16177.

[29] Bucher CG, Bourgund U. A fast and efficient response surface approach for structural reliability problems. Struct Saf 1990;7:57-66.

[30] Labeau PE, Zio E. Procedures of Monte Carlo transport simulation for applications in system engineering. Reliab Eng Syst Saf 2002;77:217-28.

[31] Naess A, Leira BJ, Batsevych O. Reliability analysis of large structural systems. Prob Eng Mech 2012;28:164-8.

[32] Melchers RE. Structural Reliability: Analysis and Prediction. second edition ed. Chichester: Wiley, 1999.

[33] Der Kiureghian A, Haukaas T, Fujimura K. Structural reliability software at the University of California, Berkeley. Struct Saf 2006;28:44-67.

[34] Amanor-Boadu V, Pfromm PH, Nelson R. Economic feasibility of algal biodiesel under alternative public policies. Renewable Energy.

[35] Coronado CR, Tuna CE, Zanzi R, Vane LF, Silveira JL. Development of a thermoeconomic methodology for optimizing biodiesel production. Part II: Manufacture exergetic cost and biodiesel production cost incorporating carbon credits, a Brazilian case study. Renewable and Sustainable Energy Reviews 2014;29:565-72. 